\title{
The development of social security policies in Greece (1974-2011) through the method of data analysis
}

\begin{abstract}
The aim of the present paper is two-fold: on the one hand, it introduces a new methodological approach in the social sciences; and on the other, it focuses on the development over time of social security policies in Greece. Multi-dimensional data analysis methods and, in particular, correspondence analysis (CA) and hierarchical cluster analysis (HCA) have been chosen as the most suitable statistical methods. Without an a priori hypothesis, these result in the depiction of the subject while allowing, at the same time, critical interpretations of the relationships that emerge between social policies. Juxtapositions of extreme situations, and medium to extreme ones, lead to useful conclusions from the perspective of correspondence analysis. In the same way, hierarchical cluster analysis results in the creation of groups consisting of years and the characteristics which determine them and deliver particular content. Finally, analysis of the subject permits the connection between developments in Greece and similar policy trends in the European Union.
\end{abstract}

Keywords: social security policies, diachronic development, data analysis methods, correspondence analysis (CA), hierarchical cluster analysis (HCA), European Union policies

\section{Introduction}

Social security policies approached in terms of their development over time (i.e. their diachronic development) are the subject of this present study. The framework is Greece during the period 1974-2011; that is to say, after the establishment of civil democracy. In particular, the discussion of the recent and continuing reforms stimulates interest in further study. There is great interest on the one hand in the socio-economic conditions of each society and, therefore, in the context of the political decisions which have been taken; and, on the other, the differing levels of criticism depending on which side these are derived, for example: the government; employers; or workers and trade unions. ${ }^{1}$

1 This article was presented as a paper to the ICIB (International Conference on International Business) conference, held in Thessaloniki on 19-22 May 2011. The author would like to express sincere thanks to referees for their real and constructive interest and recommendations, as well as their supervision of the final version of this paper. A detailed version of this paper, with full statistical and technical analysis, is available from the author. 
Besides, the specific policies followed by Greek governments are interesting in terms of their connection with relative developments in the European Union.

The main research principle of the author is the relationship over time between social phenomena, meaning that the general includes the specific. At the same time, the present study refers to an interdisciplinary approach, meaning that statistics, the law and macroeconomics are deployed in the service of understanding the dimensions of the phenomenon under analysis, as will be seen below.

Moreover, it is important to stress the new research approach introduced in this article. The term diachronic development makes a difference in that reforms of social security policies succeed one another. With the methods proposed, the continuity of the phenomenon introduces a new dimension through the relationships that emerge over time.

Unlike most previous studies that analyse specific parts of social security reforms individually (Mylonas and de la Maisonneuve, 1999), as well as others that refer to particular developments in social security legislation (Venieris, 1994), the present study proposes the diachronic development of the policies followed, covering their main features during the 1974-2011 period in a multivariable analysis. Furthermore, prior to this diachronic analysis, data analysis methods have been used to show the diachronic development of quantitative data such as unemployment and other measures of the state of the economy (Papadimitriou and Hadjikonstantinou, 2000).

With the present study, a new statistical approach, that of data analysis methods, is proposed as a new approach in the study of the development over time of particular policies, not only in the social security arena but also in that of labour relations (Maбov́ $\rho \alpha, 2005)$. It also refers to new data introduced with the present study, including

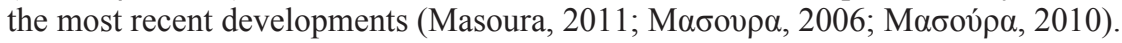

For the purposes of this study, 21 variables have been chosen as being most representative of a full description of the issue, taking into consideration that all of these variables are the subject of continuing political reforms.

These indicative variables (with their symbolism in parenthesis) are:

1. retirement age (for the general category) (gen)

2. retirement age (for people working in heavy and unhealthy professions, as well as in mines) (unh)

3. retirement age (for mothers) (mot)

4. pension with decreasing conditions of retirement (dec), constituting the total conditions of retirement

5. replacement ratio (the pension as a ratio of salary/the method of calculating pension entitlement (sub)

6. time over which pension is calculated (tim)

7. the wage in respect of which the pension is calculated (wag)

8. pension re-adjustment (the method of indexing pension increases) (rea), concerning the sum of final pension received

9. minimum pensions ( $\mathrm{min})$

10. maximum pensions ( $\max )$

11. disability pensions (dis)

12. social security contributions (con) 
13. funds consolidation (fus)

14. property exploitation of social security funds (exp)

15. employment of pensioners (lab)

16. unemployment benefit (une)

17. family benefit (ben)

18. form of the social security system (the nature of the system is) (for)

19. extension of social security (in terms of categories of people, in benefits etc) (ext)

20. participation in the administration of social security funds (par)

21. organisational structure (org) that constitute various other social security variables.

The above variables refer to the entire Greek social security system through its constituent components: the social security organisations, i.e. the Social Security Institute (IKA), mainly for wage-earners in the private sector; the farmers' security organisation (ОГА), mainly for farmers; the special funds mainly for employees of banks and public enterprises; and the state social security organisation for civil servants.

\section{Methodology}

The first step is taken by choosing the proposed most indicative variables constituting the basic components of social security policies. In this way, social security law

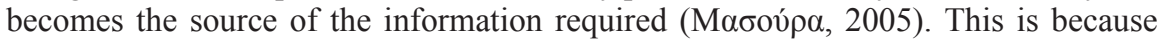
legislation is considered to be the final depiction of political will, reflecting the specific political decisions legislated for by the Greek parliament. More specifically, all national laws involving measures which refer to the 21 variables listed above over the entire period between 1974 and 2011 are examined. It should be stressed that all these variables are qualitative; they do not represent a measurable quantity, but a situation which can be symbolised arithmetically.

To this end, a numerical scale is used for the characterisation of each variable diachronically. For each variable, 1 symbolises the first legislative measure that refers to the concrete variable for the first year (or period) of the analysis (starting in 1974). In the same way, 2 refers to the second measure that is met in the following year (or period), and reflecting the respective law then in place, leading thus to the final number that characterises each variable for each year (or period). Specifically, it should be said that the numerical symbolisation shows only the change that occurs in each variable over the time under examination; there is no numerical superiority ( $\alpha \alpha \alpha \delta \eta \mu \eta \tau \rho$ íov, 2005).

An indicative example of the way in which the numerical parameterisation for the 'disablement pensions (dis)' variable works is as follows:

dis1 (1974-1980): differentiation of the criteria within the social security organisations (IKA: a full pension for a disability rate of $67 \%$; a three-quarters pension for disability rates between $50 \%$ and $66 \%$ ) (Law 1846/1951; 407/1984; etc. being the different laws for each social security fund). This numerical code characterises the years between 1974 and 1980, i.e. until the next change, being the legislative measure that was next voted through regarding the examined variable. So, subsequently as regards the development of the dis variable:

dis2 (1981-1989): enactment of the general protection of absolute disability - expansion to the social security organisations (Law 1140/1981, Article 42). 
dis 3 (1990-1991): increase in the disability rate as a condition of a disability pension (Law 1902/1990, Article 27).

dis4 (1992-2009): stricter rules for disability pensions (Law 2084/1992, Articles 25 and 49).

dis5 (2010-2011): creation of the Centre for Disability Certification, i.e. the general unified regulation concerning the determination of 'disability', accompanied by more demanding criteria for the characterisation of disability (Law 3863/2010).

When the procedure of parameterisation (or codification) for all variables is completed, an initial table of data of dimensions $38 \times 21$ is created, expressing 38 years in the lines and the 21 variables in the columns, each of which have different numbers referring to the different periods marking the development of each one, from 4 (par) up to $14(\mathrm{org})$.

However, the table to which the statistical methods are applied is not the initial table of years and variables, but the so-called logical table or 0-1 table. In this table, the lines continue to describe the years, but the variables are transformed into attributes, according to the parameterisation-codification that has been applied to each. For instance, the variable dis on the initial table becomes dis 1 , dis 2, dis 3, dis 4 and dis5 in Table 0-1. In this way, Table $0-1$ is a $38 \times 173$ table, where the 38 rows are the years (or objects) and the 173 columns are the attributes (the characteristics of the analysis).

Therefore, it is Table 0-1 to which the data analysis methods and, specifically, hierarchical cluster analysis and correspondence analysis are applied (Figure 1). This is because multidimensional analysis requires a characteristic for each year. Moreover, the sum of each line of Table $0-1$ equals 21 , corresponding to the number of variables used.

Figure 1 - Table 0-1 of the analysis

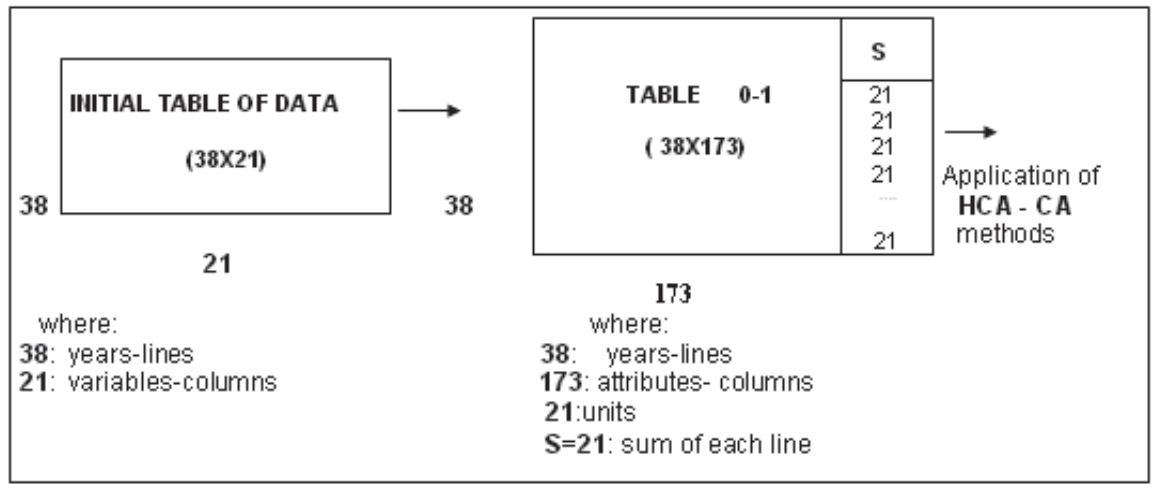

The 0 - 1 table proves to be the table that permits the multidimensional analysis of the phenomenon through the different, but complementary, role of the two proposed data analysis methods. In particular, the application of hierarchical cluster analysis (HCA) allows the creation of groups and sub-groups that are constituted by time periods and sub-periods with the corresponding attributes that characterise them. The grouping 
created by such analysis is confirmed by correspondence analysis. Correspondence analysis gives a photography or anatomy of social security policies for the time period being examined and for the variables identified during this period in the space of two dimensions.

At this point, it is useful to stress that, with these particular methods of data analysis, an analytic description of the data table consisting of qualitative variables is achieved. In this way, interpretation is easier and conclusions come without an a priori hypothesis or restriction. All the variables in the initial table have the same statistical importance (П $\alpha \pi \alpha \delta \eta \mu \eta \tau \rho i ́ o v, 2005)$ : so, the data leads to interpretations and not vice versa. On the contrary, in econometrics a hypothesis or model leads to the facts, although this serves different purposes.

Thus, the multidimensional elaboration of all variables simultaneously, and the complete description of the phenomenon across the 38 years under study, is ensured. This ability of the proposed multivariable data analysis methods, permitting the simultaneous analysis of column-points and line-points, namely the attributes, makes them the most appropriate form in the present study.

It is with the pictorial results of hierarchical cluster analysis and correspondence analysis with which the present study portrays the development over time of social security policies in Greece. This differentiates the multivariable statistical methodology from simple or dimensional approaches of classic descriptive statistics. With classic descriptive statistics, variables are examined one by one, or two by two and not all together; in contrast, data analysis shows the interaction of variables revealing, at the same time, useful information.

\section{Results of the hierarchical cluster analysis}

The eight groups which emerged from the application of hierarchical cluster analysis are presented below giving, at the same time, their arithmetical symbolisation in order to be connected later with the results of the correspondence analysis (CA):

- group A1 (1974-1983) reflects the consolidation of social security rights and represents the period where the state was more generous as far as benefits are concerned and also where the separation of funds and conditions became a reality

- group A2 (1984-1989) follows the logic of the previous group, extending what were - until then - consolidated rights

- group B1.1 (1990-1991) is the period where new data were introduced as far as the examined variables are concerned, constituting the starting point of a different mentality, a new philosophy than the prevailing one

- group B1.2.1.1 (1992-1996) is characterised mainly by the consolidation and extension of the trends that began to emerge in the previous period, with changes of a structural nature mainly in relation to issues related to the conditions of retirement and the calculation of pension entitlement

- group B1.2.1.1.2 (1997-2001), without being differentiated totally from the relative wider group from which it comes (1990-2002) includes some modifications that were introduced in the years of changes 
- group B1.2.2 (2002-2003) refers to the period of adjustments to the trends of unification in the conditions of retirement and with gravity in the organisational and functional adaptations of the social security system

- group B.2 (2004-2009) could be portrayed as the period in which the unification of funds and conditions were legislated and in which the post-1990s spirit was reinforced

- group B3 (2010-2011) concerns a period of more intensified policies, based on fiscal discipline rules.

The characterisation of these groups has been made after careful study of the results of hierarchical cluster analysis. The division of the whole period under analysis is of great importance, as this division reveals important relationships in the course of the development of social security policies over time.

For instance, the role of 1990 is critical: it is the key year for the interpretation of developments in this area. The attributes that refer to the sub-period 1990-1991 lead to the characterisation of these years as ones that introduced a new philosophy in social security. That is to say, 1990 constitutes the beginning of increases in the age of retirement, while 1991 moves in the orbit of additional measures, not only for the general category of working people (gen4, gen5) but also for special categories of insured people (unh3 and mot2, mot3). More clearly, the minimum time needed to secure a pension was at this time increased from 4050 days of work to 4500 days, increasing in this way the retirement age in the public sector and in the special funds.

The new way of calculating pension entitlement in the public sector and the special funds led to smaller pensions (sub2, sub3). Moreover, the period of calculation of the wages at which a pension was drawn was increased and fixed in the last five-year period for IKA (tim2). These two alterations imply a decrease in the pension received.

As far as the readjustment of pensions is concerned, the automatic wage increase was suppressed and indexation according to the rate of indexation among public employees established (rea4). Also, minimum pensions were disassociated from the 20 and 18-day wage $(\min 3)$.

Taking into consideration the maximum pension, a general restriction was established for the total pension $(\max 3)$. Additionally, for disability pensions an increase in the rate of disability as the criterion for granting the pension may be observed: rates of disability bigger than $80 \%$ attract a full pension; for $67 \%-79 \%$ disability a threequarters pension is paid; and for rates between $50 \%$ and $66 \%$, there is a half-pension (dis3). Moreover, increases in the contributions of IKA, the public sector, the special funds and the self-employment funds may be observed (con4).

Furthermore, as far as the property exploitation of the social security funds is concerned, regulations for more profitable and risky investments were legislated (exp3).

Finally, the extension of social security to those working in new forms of employment, such as partial employment, was constituted (ext5).

In the same way, the rest of the groups were characterised according to the attributes that form them. All these data are derived from the legislation, i.e. Law 1902/1990 and Law 1976/1991. 
It is important at this point to refer the reader to a recent paper concerning the chronological development of labour relations policies which draws useful conclusions comparing the relevant groups (Masoura, 2010).

\section{Results of the correspondence analysis}

It can be concluded from the above analysis that hierarchical cluster analysis depicts the grouping and, therefore, the relationships between the years and their attributes, reflecting the development over time of social security policies. The periods created, coupled with the most significant characteristics which refer to them, give the subgrouping a specific meaning.

Subsequently, it would be important to emphasise the descriptive, revealing - in a different way - the role of correspondence analysis. This functions in a complementary way to hierarchical cluster analysis (HCA) playing, however, a different interpretative role.

Beginning from the 1 st time period (1974-1983), i.e. group A1, the $2^{\text {nd }}$ period (1984-1989), group A2, follows. Then, there is the 3 rd period (1990-1991), group B1.1, taking us to the top of the parabola (the so-called Guttman effect) (Camiz, 2005), until the end of the 'journey'; that is, the last, or $8^{\text {th }}$, period under examination (2010-2011), i.e. group B3. In the meantime, the $5^{\text {th }}$ period (1997-2001), group B1.2.1.1.2; the $6^{\text {th }}$ period (2002-2003), group B1.2.2; and the 7th period (2004-2009), group B.2; succeed in the footsteps of the $4^{\text {th }}$ period (1992-1996), i.e. group B1.2.1.1, which is the one which has decisive importance.

This characterisation shows the succession as each group emerges from the hierarchical cluster analysis. The ‘journey' of social security policies starts from a situation in which the establishment and extension of rights prevail to reach a landmark of ideological change which is constantly intensified up to the end of the period under examination.

To make this clear, the $1^{\text {st }}$ period (1974-1983), when the basic principles of social security were established, is juxtaposed to the $8^{\text {th }}$ period (2010-2011), when the content of these principles was altered, subsequent to the 1990s change of social security philosophy.

\section{Developments in the European Union}

The introduction of this new methodological proposal leads us to a depiction of the diachronic development of social security policies in Greece, with an emphasis on the critical juxtapositions and groupings. In an attempt to interpret the development of social security policies in Greece over time, it would be useful to place the subject in the context of developments in the general European economic and political 'background'.

At the beginning of this period in Greece, the reference to the co-ordination of provisions for national social security systems is a nod towards the consolidation of 
social security rights for all working people in the European Union, regardless of the member state where these rights were acquired. ${ }^{2}$

The European Convention of Human Rights (1950) and the European Social Charter (1961) were ratified in Greece in 1984, following its accession to the European Community, and these constitute the basis of social security legislation for working people. There are no policies imposed by a common social security policy; only recommendations which serve the goals of the common market. Community Regulations 1408/1971 and 574/1972 are the points of reference as regards the initial European social security regulations.

The Community intervenes only when a member state cannot resolve issues of social security. Thus, the period between 1974 and 1989 coincides with the general establishment of social security regulations in favour of working people.

On the contrary, the second half of this period between 1990 and 2011 denotes the entrance of new conditions. The guidelines of the White Paper, the Treaty of Maastricht (1992) and the Treaty of Amsterdam (1997) promote the co-ordination of national policies for the reinforcement of social policy towards a more social union in the EU. In addition, the Stability and Growth Pact recommends fiscal discipline through the reduction of pensions expenditure in accordance with the rules of Economic and Monetary Union (Рo $\left.\mu \pi \lambda_{\lambda} \eta \varsigma, 2004\right)$.

These policies, which entered into force during the 1990s, reveal a trend for cutting social security benefits as one part of a set of policies aimed at reducing wage and nonwage costs. This legislation was gradually reinforced in the 1990-1991, 1992-1996, 1997-2001, etc. periods.

Moreover, the Treaty of Nice (2001) supports and supplements, in the context of social policy, the actions and rights of member states in the area of social security and the social protection of working people. Regardless, a European conference at The Hague on the subject of 'The challenge of social security' in 2002 showed the progressive and constant course being charted towards a European social security system to which all member countries are bound. The common characteristics of this system appear mainly to concern subjects such as contributions; the social security cover of working people; the sufficiency of social security benefits (the rate of income replacement, the indexation of pensions); the conditions of retirement (normal retirement age, minimum service periods before retirement); the significance held by disability; the retirement of mothers; the recognition of military service; the role that periods of study hold in the calculation of pensions; etc.

The role of the state is limited to the guarantee of the legislative, organisational and functional conditions for social security protection without, however, the state itself being compelled to provide the necessary social security benefits. Furthermore, the tendency towards a shrinking of the role of the state, as well as the transformation of social security systems from systems of defined benefits into systems of defined contributions, is transferring responsibility for pensions to insured people themselves.

2 See Article of 51 of the Treaty of Rome - Article 42 of the Unified Treaty on the foundation of the European Community; and Article 100 of the Treaty of Rome - Article 94 of the Unified Treaty on the foundation of the European Community. 
Additionally, the support of the coexistence of a social security system with elements of a private one constitutes one more direction for European systems of social security.

In the same way, the spring 2003 meeting of the EU Council of Ministers, through the open method of co-ordination, recommended the control of social security expenditure (2000-2050) on account of fiscal restrictions. It is this same attitude that was reflected in the decisions of the next councils of the heads of the European Union. Moreover, the Lisbon strategy goals for a more competitive European economy - up to 2010 initially and then until 2020 in a revised strategy - are revealing.

The measures being taken in Greece are justified by the official state position that some privileges - such as pensions at younger ages - must be rationalised and a unification of conditions achieved. The other side of this is that trade unions are, in general, against measures that, in their view, downgrade working people's standards of living. In contrast, employers are insisting on reducing non-wage costs.

In parallel to their ideological base lie the political positions of the Greek political parties. These political views extend from the perception of social security as a means of reducing state expenditure and helping private investment, to an approach which sees it as a vehicle for the expansion of social rights.

It is obvious, therefore, that the Greek social security system has, for some time, been changing its form and facing up to the need to adapt to the new economic and

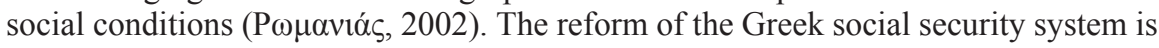
being realised exactly from the perspective of this mentality: social security policies are following the different economic and social conditions.

Ultimately, the last years of the period under examination (2010-2011) are of critical importance as radical measures concerning the content of social security are being introduced. This is the period of economic crisis in Greece. The statement on the support of Greece by Eurozone members to safeguard financial stability outlines cutbacks in social benefits, such as pensions, as well as more intensive measures, such as tougher pensions contributions and making economies in state revenues in return for the granting of loans. The legislation of both 2010 and 2011 reveal the general economic and political priorities.

This point concludes our criticism of the social security which have been taken. It is important to stress that the objective reality of the diachronic development of social security is subject to many different and usually conflicting interpretations, depending on the perspective from which the criticism is made. On the one hand, the government supports the need for unavoidable tough measures because of the uncontrolled level of state debt. On the other hand, trade unions and working people are opposed to the unfair and one-sided measures - in their view - being taken since the incomes of low-paid workers and pensioners are being unfairly affected.

Contemporary Greek society is bombarded with articles and discussion over the Memorandum: namely, the causes, consequences and solutions, reflecting differing points of view. Fiscal discipline is affecting social security policies directly, and these are, therefore, part of the whole discussion. 


\section{Conclusions}

Data analysis, especially through the methods of hierarchical cluster analysis and correspondence analysis, are proven to provide social sciences with a useful methodological tool as far as the study of state policies over time is concerned. A study of social security policies shows that the grouping together of periods and their characteristics and attributes reveal hidden relationships between them, something which is significant for the analysis of a long time period and of a great number of data at once. It is also important to focus on homogenous situations that are juxtaposed to the opposing ones.

In brief, we believe we have accomplished our purpose for the present article. The introduction of a new methodological approach opens new perspectives in the field of social sciences. Apart from that, practically, the creation of data legislation should be useful to all those involved in social security. In addition to this, new dimensions of study may emerge theoretically. Constant improvements to statistical analysis software programs should guarantee a more elaborate and better technical depiction of largedimension tables.

We have been able to deliver an initial picture of the development over time of social security. Data analysis indeed portrays the diachronic continuity of the phenomenon. Besides, economic and political developments seem not to stop, something that gives the study the perspective from which to proceed.

Extending the analysis, and bound to the belief that social security policies are only one part of the total socio-economic system, would require the study to focus on different theoretical schools of thought (neo-liberalism, Keynesianism, Marxism) that are reflected in the programmes of the relevant political parties.

In a dialectic perception, the developments should be connected to the wider European Union and international relationships; for instance, the nature of the social state before and after 1990, when worldwide developments were of critical importance, such as the overthrow of the Soviet Union.

All of the above point to the need for criticisms of a macroeconomic theme, such as social security, to be multi-dimensional. Data analysis methods provide a methodological tool that depicts the reality and its cogent facts, giving food for thought on such a multi-dimensional subject.

Ultimately, the enrichment of this study with other policies, such as education policy, health policy and economic policy, should be the aim of further research, as a means of delivering useful practical and theoretical information derived from this rapidlychanging world.

\section{References}

Aldenderfer, M. S and R. K Blashfield (1984) Cluster Analysis Sage University Paper 44: Beverly Hills.

Benzécri J.-P (1980) Analyse des Données, T.1 : La Taxinomie Dunod: Paris.

Benzécri J.-P (1982) Analyse des Données, T.2: L’Analyse des Correspondances Dunod: Paris. 
Benjecri J.-P (1992) Correspondence Analysis Handbook New York: Marcel Dekker.

Beh E. J (2004) 'Simple Correspondence Analysis: A Bibliographic Review' International Statistical Review 72(2): 257-284.

Blasius, J and M. J Greenacre (1994) 'Computations of Correspondence Analysis' in J Blasius and M Greenacre (Eds.) Correspondence Analysis in the Social Sciences San Diego Academic Press, pp. 53-78.

Caillez, F and J-P Pagés (1976) Introduction á l'Analyse des Données SMASH: Paris.

Camiz, S (2005) 'The Guttman effect : its interpretation and new redressing method'

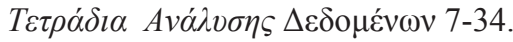

Commission Européenne (1994) Politique sociale européenne: une voie á suivre pour l’Union: Livre Blanc Com(94)333, 27 July 1994.

High Level Group chaired by Wim Kok (2004) Facing the challenge: The Lisbon strategy for growth and employment.

Greenacre, M (1993) Correspondence Analysis in Practice: Academic Press, London.

Official Journal of the European Union C306, 17 December 2007: Treaty of Lisbon.

Masoura, E (2010) Labour relations policies in Greece during the period 1974-2010: The developments of the European Union International conference on international business (ICIB): Thessaloniki.

Mylonas, Paul and Christine de la Maisonneuve (1999) The problems and prospects faced by pay-as-you-go pension systems: a case study of Greece Economic Department Working Papers No. 215: ECO/WKP 7: OECD.

Papadimitriou, Y and G. Hadjikonstantinou (2000) 'Evolution diachronique de la position relative des 15 pays members de l' union europeene sous l' effort de la convergence' Vie et Sciences Economiques 156: Paris.

Stevens, J (2002) Applied Multivariate Statistics for the Social Sciences New Jersey: Lawrence Elbaum Associates.

Van de Velden, M (2000) Some Topics in Correspondence Analysis Tinbergen Institute Research Series No. 238: Amsterdam.

Venieris, D (1994) The Development of Social Security in Greece, 1920-1990: Postponed Decisions $\mathrm{PhD}$ thesis, University of London.

Official Journal of the EC C340 10 November 1997 Treaty for the European Union.

Official Journal of the EU C80 10 March 2001 Nice Treaty.

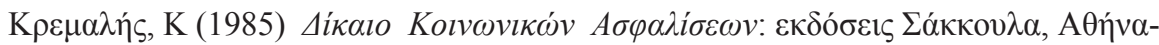

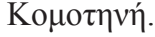

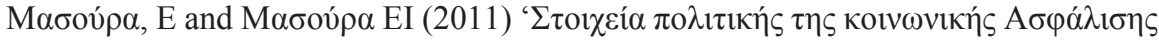

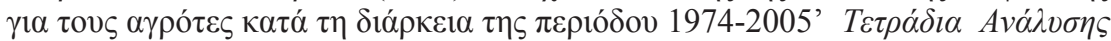
$\Delta \varepsilon \delta o \mu \varepsilon \dot{v} \omega \nu \tau .12, \sigma .127-138$. 


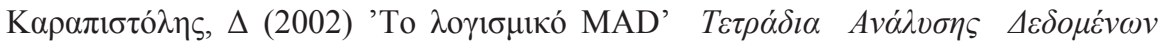

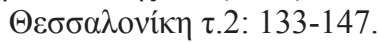

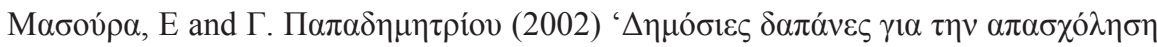

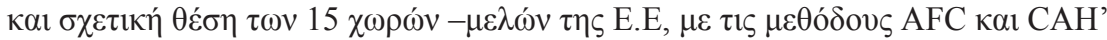

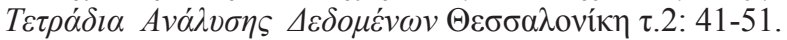

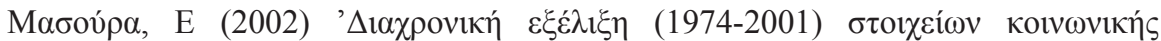

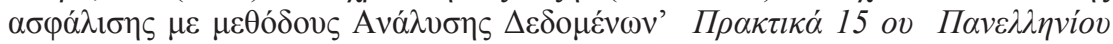

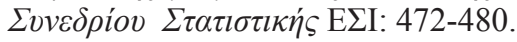

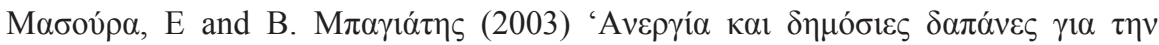

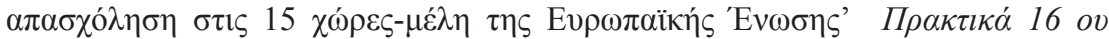

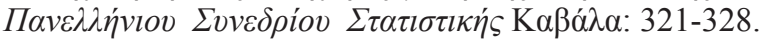

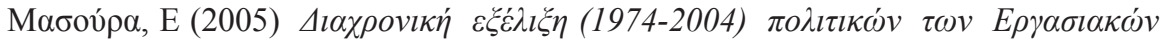

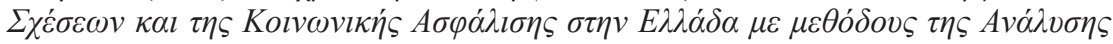

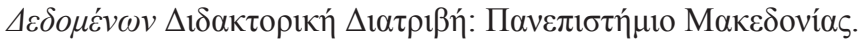

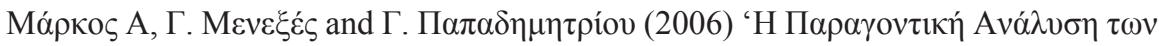

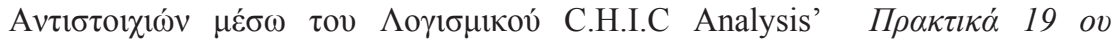

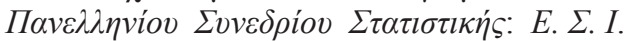

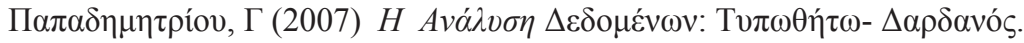

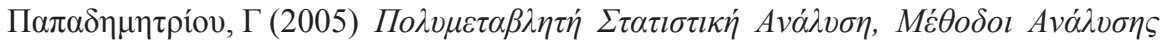

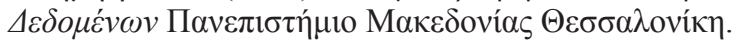

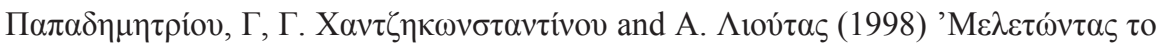

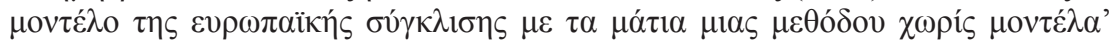

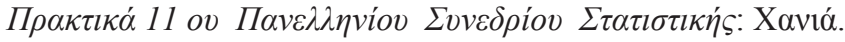

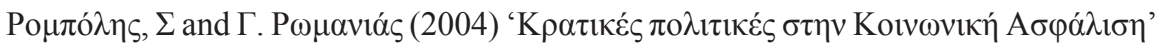

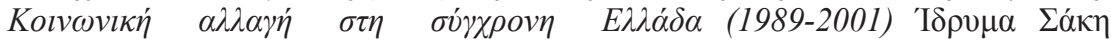
K $\alpha \rho \alpha ́ \gamma 1 \omega \rho \gamma \alpha$.

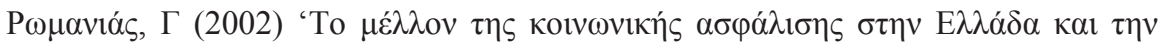

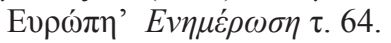

